\title{
Gênero e a Questão do Refúgio: As lacunas jurídicas de proteção à mulher refugiada.
}

\author{
Louise Leoni Abreu ${ }^{1}$
}

\section{Resumo}

O presente estudo foi desenvolvido a partir do grupo de pesquisa da Universidade Federal do Rio de Janeiro "Fluxos Migratórios no Mundo Contemporâneo", sob uma perspectiva crítica do Direito Internacional dos Refugiados e à estrutura do ACNUR. A base metodológica utilizada foi a leitura de autores que se dedicam ao tema e que foram estudados no grupo de pesquisa, além da utilização de uma perspectiva do feminismo interseccional crítico. $\mathrm{O}$ trabalho oferece uma análise acerca da lacuna jurídica existente na Convenção Relativa ao Estatuto dos Refugiados de 1951 e ao Protocolo Adicional de 1967 do Alto Comissariado das Nações Unidas para Refugiados (ACNUR) que apenas menciona cinco razões para o reconhecimento de um indivíduo como refugiado: um temor de perseguição baseado na raça, religião, nacionalidade, pertencimento a um grupo social específico ou opinião política. Ao estabelecer apenas cinco razões, as experiências femininas relacionadas ao temor de perseguição são desconsideradas pela organização, baseando-se apenas na experiência masculina. Assim, a perseguição relacionada à razão de gênero é apenas considerada por guias de diretrizes posteriores ao estatuto, o que sob a perspectiva jurídica dá menor importância às questões de gênero à solicitante de refúgio, sendo estas desconsideradas. Essa desconsideração possui motivações políticas e sociais e suas consequências também são vistas no Estado e na sociedade. Há uma motivação nesse sentido pela violência de gênero ser comumente relacionada a ambientes privados, não sendo a mulher protegida pela esfera pública. Nesse sentido, busco realizar uma crítica à ausência da perseguição de gênero no Estatuto.

Palavras-chave: Refúgio, Gênero, Mulher, Estatuto, ACNUR

\section{Abstract}

The present study was developed from the research group of the Federal University of Rio de Janeiro "Migratory Flows in the Contemporary World", from a critical perspective of International Refugee Law and the structure of UNHCR. The methodological basis used was the reading of authors who are dedicated to the subject and who were studied in the research group, besides the use of a critical intersectional feminism perspective. The paper provides an analysis of the legal gap in the 1951 Convention Relating to the Status of Refugees and the 1967 Additional Protocol of the United Nations High Commissioner for Refugees (UNHCR) which mentions only five reasons for the recognition of an individual as a refugee: fear of persecution based on race, religion, nationality, membership of a specific social group or political opinion. In establishing only five reasons, the female experiences related to the fear

\footnotetext{
${ }^{1}$ Aluna da graduação da Faculdade Nacional de Direito da Universidade Federal do Rio de Janeiro
} 
of persecution are disregarded by the organization, considering only the male experience. Thus, gender-related persecution is only considered by post-status guidelines, which from the legal perspective gives less importance to gender-based persecution, those being disregarded. This disregard has political and social motivations and its consequences are also seen in the State and in society. There is a motivation in this sense for gender violence to be commonly related to private environments, where women are not protected by the public sphere. In this sense, I seek to criticize the absence of gender persecution in the Statute.

Key words: Refugee, Gender, Woman, Statue, UNHCR

\section{Introdução}

A crise dos refugiados é uma realidade global, intensificada por fronteiras que se fecham e fluxos que se acentuam. Hoje temos mais de 67 milhões de refugiadas ${ }^{2}$, incluindo os deslocados internos, de acordo com os dados do Alto Comissariado das Nações Unidas (ACNUR). A refugiada mulher encontra demandas e dificuldades específicas ao longo do processo de fuga.

Apesar de não incluída na Convenção Relativa ao Estatuto dos Refugiados de $1951^{3}$ em sua definição de refugiado, a perseguição de gênero encontra proteção no Guia da ACNUR, nas Diretrizes sobre Proteção Internacional n 1 , Perseguição baseada no Gênero, no contexto do Artigo 1A(2) da Convenção de 1951 e Protocolo de 1967 relativo ao Estatuto dos Refugiados de $2002^{4}$, como um guia com diretrizes que expandem o conceito de refugiada a partir dos pontos que já continham no Estatuto anterior.

De acordo com o ACNUR,cerca de $49 \%$ da população de refugiadas nos últimos anos são mulheres (ACNUR, 2014, p. 36). Visto isso, pelo menos 8,5 milhões de mulheres estão fugindo de seu país de origem em resposta à violação de diversos direitos humanos. ${ }^{5}$ As mulheres fogem pelas mesmas razões que os homens, porém, sua condição de gênero implica em algumas violações específicas - como o casamento forçado, estupro generalizado, mutilação genital feminina ou a discriminação cumulativa de gênero.

\footnotetext{
${ }^{2}$ Será utilizado aqui o termo "refugiada" para indicar a pessoa que busca o reconhecimento como tal e o solicita a um Estado por um grave temor de perseguição. Assim como proposto pela autora Emma Haddad (2008), este texto entende ser a "refugiada" tanto o homem refugiado quanto a mulher refugiada assim como crianças. A escolha do substantivo feminino é, portanto, proposital, e será usado como neutro. Serão consideradas refugiadas aquelas que saem de seus lugares de origem forçadamente por um grave temor de perseguição.

${ }^{3}$ Doravante mencionado Estatuto de 1951

${ }^{4}$ Doravante mencionado Diretrizes de 2002 do ACNUR

${ }^{5}$ De acordo com o Global TrendsReport do ACNUR, 51,2 milhões de pessoas sofrem com o deslocamento forçado ao redor do mundo. Desse total, 16,7 milhões são refugiadas, 33,3 são deslocados internos e 1,2 milhões são solicitantes de refúgio (ACNUR, 2014, p.3)
} 
Para compreender o que há por trás do refúgio e seu reconhecimento, é necessário considerar dois aspectos: motivação das refugiadas e decisão dos Estados (HADDAD, 2008, pp. 32-33). A motivação ética seria considerar as questões humanitárias envolvidas e o entendimento por parte das autoridades de que há um perigo e uma nítida perseguição a essas pessoas. Já a decisão política é o interesse estatal no seu reconhecimento. Assim, o refúgio é a união desses dois aspectos relacionados.

Nos últimos anos, principalmente após os ataques do dia 11 de setembro de $2001 \mathrm{em}$ Nova Iorque e os subsequentes ataques terroristas em Madrid, as refugiadas presentes nesses locais foram pressionadas, pelo desconhecimento por parte dos nativos locais do estrangeiro. Assim, os estrangeiros são acusados pelos atos de terrorismo nessas localidades. Consequentemente, há um crescente medo em relação à aceitação de refúgio e a refugiadas. (BAUMAN, 2008, pp.132-139) Ao passo que esse medo cresce pelo terrorismo, a grande mídia e a difusão das redes sociais divulgam imagens de campos de refugiados na África e Ásia, onde há um enorme número de $\operatorname{pessoas}^{6}$ que necessitam da ajuda humanitária para sobreviver (FREEDMAN, 2015, pp. 1-3). Esses campos de refugiadas criam além de uma situação de dependência, um cerceamento da liberdade dessas refugiadas que vivem em campos. Dessa forma, pode-se dizer que o temor cresce conforme o número de refugiadas no planeta.

Apesar da conjuntura atual de medo em relação à proteção das refugiadas, a criação de uma proteção internacional às refugiadas apresentou em sua estrutura restrições marcadas pelo contexto político de Guerra Fria, demonstrando que as relações de poder trazem consequências legais. (WALDELY, 2014)O surgimento de um Estatuto específico para refugiadas amenizam o vácuo de proteção existente no Direito Internacional para a proteção desse grupo vulnerável, já que não podem se beneficiar do direito interno de seu país de origem.

A estrutura de sociedade em que vivemos se baseia no patriarcalismo, baseada na autoridade masculina sobre a mulher. Elshtain (1981) argumenta que os homens são guiados pela vida pública enquanto as mulheres são marginalizadas pela esfera privada. Dessa forma, o mesmo se pode dizer sobre a violência específica de gênero que é comumente relacionada ao ambiente doméstico, dificultando uma proteção institucionalizada à mulher. O próprio Direito agrava essa dicotomia, pois o que é doméstico, não se encontra em sua esfera de

${ }^{6}$ De acordo com o ACNUR, há uma estimativa de 13,2 milhões de pessoas que vivem em campos de refugiados oficializados ao redor do mundo, podendo esse número ser maior ao contabilizar os campos de refugiados nãooficiais. 
proteção. (OLSEN, 2009)Assim, as atividades consideradas importantes para a sociedade, que são as da esfera pública, são protegidas pelo Direito. Já as questões pertencentes à esfera doméstica são deixadas de lado. Isso se reflete no não estabelecimento da proteção específica das refugiadas mulheres, que, de acordo com o Estatuto do ACNUR, não incluiu o grave temor de perseguição por razão da violênciade gênero.

O Estatuto inclui apenas cinco razões para a solicitação do refúgio: um temor de perseguição baseado na raça, religião, nacionalidade, pertencimento a um grupo social específico ou opinião política. As definições devem ser expandidas para possuir novos significados para acompanhar a experiência das populações e categorias sociais a partir de sua ocorrência e publicidade. Especificamente o conceito de refugiada foi desenvolvido sob uma perspectiva europeia e cega em relação ao gênero. (HAJDUKOWSKI-AHMED, 2008, pp. 2830) A refugiada é tratada comumente pelo Estatuto sobre o termo genérico "pessoa", sem levar em consideração suas especificidades do gênero feminino e as diferentes opressões que a mulher pode sofrer em relação ao homem.

As diretrizes do ACNUR em relação à perseguição em razão da violência de gênero são um exemplo de soft law, que de acordo com Bertoldi e Oliveira (2010), é um direito que é maleável e não obrigatório. Essas diretrizes não são, por exemplo, assinadas pelos mesmos países signatários do Estatuto dos Refugiados, gerando uma lacuna jurídica quanto à proteção da refugiada mulher por razão de violência de gênero.

A lacuna jurídica torna-se, então, mais uma forma de violentar essas mulheres que saem forçadamente de seu lugar de origem, afinal, o não reconhecimento no processo de solicitação de refúgio acaba se tornando mais uma barreira ao local ao qual se destina.

\section{A Convenção de 1951 e a Invisibilidade da Violência de Gênero}

O refúgio surgiu como instituto jurídico no início do século $\mathrm{XX}$, no escopo da Liga das Nações, com a preocupação das pessoas que fugiam da recém-criada União das Repúblicas Socialistas Soviéticas com o Alto Comissariado para os Refugiados Russos ${ }^{7}$, conforme ensina Liliana Jubilut (2007, p. 73-75). Logo após, com um atendimento

\footnotetext{
${ }^{7}$ O Alto Comissariado para Refugiados Russos surgiu no âmbito da Liga das Nações em resposta ao grande número de pessoas que saíram da recém-criada União das Repúblicas Socialistas Soviéticas motivada em razão da situação política e econômica do país, especialmente os que fugiram por se oporem ao regime. (JUBILLUT, 2007).
} 
descentralizado, surge o Escritório Nansen Para Refugiados ${ }^{8}$, com o mérito da elaboração de um instrumento jurídico internacional sobre as refugiadas, a Convenção de 1933.

Após o Escritório Nansen, outras organizações surgiram nesse sentido, como Alto Comissariado para os Refugiados Judeus provenientes da Alemanha, todos com duração temporária e prazo para término. Esse prazo é reflexo de uma característica dos institutos de proteção à refugiada, que possuem um prazo de validade para seu término, na crença de que o fluxo migratório cessará ao fim de um evento específico como uma guerra ou um governo, como no caso do Alto Comissariado para os Refugiados Judeus provenientes da Alemanha.

Pode-se citar ainda a tentativa estadunidense, com a criação do Comitê Intergovernamental para os Refugiados. Com o fim da Segunda Guerra Mundial, surge a Organização das Nações Unidas (ONU), que desde sua fundação mostrou preocupação com a questão das refugiadas. Criou a resolução A/45, de 12.02.1946, que apontou as bases de atuação da ONU na questão das refugiadas e a resolução 15. XII. 46.18 de 1948, que iniciou o processo de criação da Organização Internacional para Refugiados. O fim da Organização Internacional para Refugiados data de 1952, por também possuir característica temporal.

O ACNUR surge apenas em 1950, no âmbito da ONU, porém, como uma organização autônoma. $\mathrm{O}$ marco de proteção às refugiadas no sentido moderno vem com a Convenção de 1951 que estabelece critérios bem definidos para o reconhecimento da refugiada como tal. Esta convenciona cinco motivos que asseguram o refúgio, a partir de um grave temor de perseguição: a raça, a nacionalidade, a opinião política, a religião e o pertencimento a um grupo social. Essas razões configuram uma preocupação com pilares da Revolução Francesa: a Liberdade, a Fraternidade e a Igualdade (JUBILUT, 2007, p. 113).

Ao longo dos anos 80, houve grande movimentação por parte das mulheres, advogando pela causa de políticas específicas de gênero em relação à proteção dos Direitos Humanos. Esse movimento conseguiu alcançar a pauta internacional, conseguindo estabelecer uma relação com a questão das refugiadas. A violência sexual perpetrada contra mulheres refugiadas foi elencada pela primeira vez naConferência Mundial do Ano Internacional da Mulher", realizada no México, com a "Primeira Pesquisa Mundial sobre o Papel da Mulher

\footnotetext{
${ }^{8}$ O Escritório Nansen surgiu em 1924 para alargar a proteção de outros povos como os armênios que sofreram com o primeiro grande genocídio da história da humanidade, pois o Alto Comissariado para Refugiados Russos apenas contemplava a população russa para a solicitação do refúgio (Ibidem, 2007). Seu criador, dr.Nansen em 1938 ganhou o Nobel da Paz.

${ }^{9}$ A Conferência Mundial do Ano Internacional da Mulher foi patrocinada pela Organização das Nações Unidas e realizada na Cidade do México em 1975 e contou com a participação de mais de 8 mil mulheres de 113 nacionalidades, além da presença de organizações governamentais e não governamentais.
} 
em Desenvolvimento". Com os resultados dessa pesquisa, o ACNUR apresentou um trabalho na Conferência da Metade da Década da Mulher em Copenhagen em 1980, intitulado "A Situação da Mulher Refugiada ao Redor do Mundo" pautado na violência sexual sofrida pelas solicitantes de refúgio. Na Alemanha, houve um movimento de organizações nãogovernamentais em 1984 mobilizaram pesquisas em relação à violência sexual sofrida pelas solicitantes de refúgio (MOUSSAet al., 2009, p. 2).

Embora o êxodo e a violação a direitos humanos sempre existissem, o grande número de mulheres refugiadas ficou evidente após o desenvolvimento dessas pesquisas. Ao longo dos anos 80 houve outras conferências expressivas sobre a questão da mulher como a Conferência Mundial do Final da Década da Mulher no Quênia, que contou com a realização e aprovação do documento "Estratégias Encaminhadas para o Futuro do Avanço da Mulher". Em 1985, surge o Grupo de Trabalho sobre a Mulher Refugiada no Canadá (Ibidem, 2008, pp. 2-3). Essas conferências e trabalhos mostram uma crescente demanda em relação a essa “maioria esquecida” (MOUSSA et al., apud CAMUS-JACQUES, 2009, p.2).

Em 1991, o ACNUR criou as primeiras Diretrizes sobre a Proteção Internacional perseguição baseada no gênero. Dessa forma, no início dos anos 90 foi reconhecida a existência da perseguição baseada em razões de gênero por parte do ACNUR. Porém, isso não foi suficiente para a proteção das mulheres que se refugiam por violência de gênero, pois o Estatuto de 1951 - que é a principal fonte jurídica do ACNUR e o documento no qual Estados podem ser signatários, diferentemente do Guia de Diretrizes - permaneceu apenas reconhecendo cinco razões para sua aceitação.

Posteriormente, em 2002, o ACNUR reeditou suas Diretrizes sobre a Proteção Internacional na Perseguição de Gênero, resultado do Segundo Grupo de Consultas Globais sobre a Proteção Internacional após reunião de especialistas em San Remo, Itália, fazendo algumas alterações uma década depois para uma melhoria de suas diretrizes, adequando aos padrões que a sociedade demandava e necessitava no novo século.

Apesar de uma melhoria do ponto de vista legal, com a edição e reedição de diretrizes norteadoras para os países aplicarem em relação a situações nas quais há perseguição em razão de gênero como justificativa para a solicitação do status de refugiada, a estrutura das sociedades de onde essas mulheres saem e para as quais essas se destinam é patriarcal, o que dificulta sua permanência em algum local de maneira segura. $\mathrm{O}$ medo aliado à opressão patriarcal é mais uma barreira para que essas mulheres consigam reconstruir suas vidas fora de seu local de origem. 
A convivência em uma sociedade de estrutura patriarcal é um elemento comum a praticamente todas as mulheres, e faz com que muitas delas se refugiem por tais razões. A violência de gênero possui várias formas, entre elas, o casamento forçado, a mutilação genital feminina, a discriminação de gênero, o estupro coletivo de mulheres.

\section{As Diretrizes do ACNUR relativas à perseguição baseada no gênero}

Sob a perspectiva das três vertentes de proteção dos direitos humanos - o Direito Internacional dos Direitos Humanos, o Direito Internacional Humanitário e o Direito Internacional dos Refugiados - o objetivo é proteger a vida do ser humano sob qualquer circunstância, mesmo que em vertentes $\operatorname{separadas}^{10}$ (DE PAULA \&PRONER, 2008). Entretanto, a própria proteção e suas vertentes são baseadas em uma perspectiva androcêntrica, considerando apenas a experiência masculina sob uma perspectiva europeia como base de sua criação. Dessa forma, a própria protetiva desenvolvida em nome dos direitos humanos não contempla de maneira eficaz todos os seres humanos - especialmente aqui, destaco as humanas, mulheres, a "maioria esquecida".

O conceito de refugiada é transformado de acordo com o período histórico e motivações políticas. Dependendo do contexto social e histórico, haverá uma definição para quem seria reconhecida como refugiada. Assim, pode-se afirmar que o conceito de refugiada é fluido e dinâmico. Por essa razão, constantemente as diretrizes são renovadas.

Essas constantes alterações revelam uma burocratização para o reconhecimento de um indivíduo como refugiado, ou seja, ele é uma abstração, uma "identidade estereotipada" (HADDAD, 2008). Esse estereótipo não incluiu a perspectiva feminina como uma motivação para a solicitação do refúgio e isso demonstra que incluir a perseguição em razão do sexo não era um interesse para o ACNUR na elaboração de seu estatuto. Mesmo que as diretrizes sejam constantemente atualizadas, isso não acontece com o Estatuto de 1951, que mantém as mesmas cinco razões para o grave temor de perseguição, sendo a refugiada enxergada como algo imutável.

O primeiro documento que estabeleceu que as mulheres podem ser consideradas um grupo social específico no reconhecimento como refugiadas data de 1985. Logo depois, em

\footnotetext{
${ }^{10}$ A teoria das três vertentes dos Direitos Humanos primeiramente foi trazida por Augusto Cançado Trindade, em seu livro "Tratado de Direito Internacional dos Direitos Humanos" em que o autor explica que é necessário superar a divisão entre três vertentes, uma vez que os direitos humanos devem proteger a vida humana sob qualquer circunstância.
} 
1991, as primeiras guias do ACNUR para proteção foram elaboradas. O Canadá foi o primeiro país a estabelecer seus guias para proteção baseada na perseguição de gênero em 1993 e os Estados Unidos em 1995. Essa evolução é uma resposta a uma constante demanda social de emancipação da mulher, as convenções realizadas a partir dos anos 80, pesquisas desenvolvidas por agentes tanto governamentais quanto não governamentais.

Em 2002, o Guia sobre Perseguição baseada em Gênero foi atualizado pelo ACNUR, fornecendo uma fonte jurídica para os países adotarem a medidas desenvolvidas. Entretanto, as medidas na verdade são uma leitura extensiva e amplificada do Estatuto de 1951, ou seja, o temor de perseguição em razão de gênero propriamente dito não foi adicionado, mas adequado aos parâmetros que já existiam, o que dificulta sua aplicação legal na prática.

Em resposta a essa constante preocupação social em relação a emancipação da mulher, em 2011, o ACNUR apresentou a Ação Contra a Violência Sexual e de Gênero ${ }^{11}$, voltado para fornecer auxílio à proteção das mulheres e meninas, bem como homens e meninos que sofrem com a violência sexual e de gênero, de acordo com seu próprio sumário executivo. A própria ação, entretanto, fortalece a ideia de que as mulheres possuem atenção adequada pela desigualdade do gênero e discriminação.

O Resumo das Conclusões do Comitê Executivo relativo à violência sexual e de gênero reforçam a importância do planejamento sensível a gênero e que os programas do ACNUR devem salvaguardar os direitos das mulheres. A partir disso, pode-se concluir que o próprio ACNUR reconhece a diferença no tratamento da mulher quanto sua violência sofrida e se vê na responsabilidade de protegê-la.

Dentro das Diretrizes sobre a Proteção Internacional elaborada em 1991 cabe mencionar que elas não buscam adicionar a perseguição baseada no gênero, mas analisar as cinco razões sob uma perspectiva de gênero para serem reconhecidas dentro de suas especificidades. Essas Diretrizes, dessa forma, buscam interpretar a Convenção de 1951, fazendo uma releitura de seus termos, trazendo uma perspectiva baseada no gênero para sua perseguição.

\footnotetext{
${ }^{11}$ Essa ação foi baseada em uma avaliação independente realizada em 2008 para prevenir e responder adequadamente os casos de violência sexual e de gênero, ponderando os esforços do ACNUR. Ela foi elaborada por funcionários do ACNUR, parceiros, população de interesse, governos e especialistas. Suas estratégias, de acordo com a própria ação em seu sumário executivo são: (I) proteção de crianças vulneráveis à violência sexual e de gênero, (II) abordagem do sexo pela sobrevivência como um mecanismo de enfrentamento em situações de deslocamento, (III) engajar homens e meninos, (IV) fornecer ambientes e acesso seguro a energia doméstica e recursos naturais, (V) proteção de gays, lésbicas, bissexuais, travestis, intersexuais (LGBTI) vulneráveis à violência sexual e de gênero e (VI) proteção de pessoas com deficiência vulneráveis à violência sexual e de gênero.
} 
Apesar do ponto positivo do desenvolvimento dessa legislação protetiva em relação à perseguição por razões de gênero, ainda é um desafio persuasivo à mulher requisitar o refúgio por essas razões (FOSTER, 2014, p. 18).

Do ponto de vista jurídico, o conflito entre normas de normas internacionais com normas internas é comum, pois as normas internacionais são recepcionadas nos ordenamentos jurídicos internos por diretrizes estabelecidas nos seus respectivos textos constitucionais. (SOARES, 2009) O conflito pode existir através de Estatutos e tratados do qual o país é signatário, entretanto, o mesmo não acontece com as Diretrizes de 2002. As diretrizes acabam se tornando orientação interpretativa das normas do estatuto, não possuindo um embasamento legal e, portanto, não aplicável aos tribunais e aos solicitantes de refúgio em geral, que como no caso de Zeinab, preferem utilizar outras justificativas para a solicitação. Pode-se considerar, então, que do ponto de vista prático essas diretrizes são ineficazes, não fornecendo a proteção necessária a um grupo tão vulnerável como as refugiadas.

Connie Oxford (2014, p. 162-164) delineou cinco linhas de pensamento - vítimas de gênero; hierarquia do dano ao gênero; androcentrismo ${ }^{12}$ contínuo; credibilidade é gênero e conhecimento é poder - nos quais ela discorre exemplos aos quais as mulheres foram forçadas a mentir para solicitar o refúgio ou que de alguma forma elas perderam totalmente a credibilidade diante do juiz em suas entrevistas, pois a palavra de um homem seria mais confiável do que a de uma mulher. Ela cita que em alguns casos, há até mesmo desinteresse, uma vez que o comportamento delas não era permitido em seu país de origem, portanto, as atitudes tomadas pelos cidadãos ou pelas autoridades daquele país se tornam aceitáveis. $\mathrm{Ou}$ seja, do ponto de vista prático, a aplicabilidade reflete a estrutura da sociedade - que se desinteressa na proteção das mulheres, o que torna ainda mais problemática a não inclusão no texto do Estatuto de 1951 a perseguição em razão de gênero.

É importante mencionar que as Diretrizes de 2002 do ACNUR, além de mencionarem as mulheres como grupo a ser protegido de maneira específica, também incluem meninas. $\mathrm{Ou}$ seja, as meninas não são vistas dentro do grupo "crianças", isso traz um entendimento que o Estatuto reconhece que meninas também podem ser vítimas de uma perseguição em razão de seu gênero. Violências como mutilação genital, casamentos forçados e a própria violência doméstica são problemáticas enfrentadas por essas meninas e podem ser razões pelas quais

\footnotetext{
${ }^{12}$ Androcentrismo de acordo com Carvalho, Andrade e Junqueira (2009) é a experiência masculina é considerada a experiência geral de maneira universalizada, seguindo um modelo hegemônico do homem dessa forma, não contempla a experiência feminina, não admitindo mulheres em posições de privilégio e poder.
} 
elas saiam forçadamente de seu local de origem para outro com temor dessa perseguição. Pode-se considerar, dessa forma, um ganho e um avanço essa consideração.

Por outro lado, um ponto relevante a ser destacado acerca das diretrizes é que, com uma leitura crítica são incluídas mulheres cisgênero ${ }^{13}$, só mencionam as transexuais e travestis ao falar sobre o pertencimento a um grupo social específico. Nesse sentido, pode-se dizer que a mulher transgênero ${ }^{14}$ não possui o amparo na integralidade do documento. Há de se mencionar as Diretrizes do ACNUR sobre Proteção Internacional n. 9 sobre as Solicitações de Refúgio baseadas na Orientação Sexual ou Identidade de Gênero de 2012, que fornece um guia sobre o grupo, entretanto, ao diferenciar a perseguição sofrida entre essas mulheres em outro Guia de Diretrizes, o ACNUR não contempla todas as mulheres que podem sofrer grave temor de perseguição em razão de gênero, mais uma vez se mostrando insuficiente. Ao sair de sua localidade para outra forçadamente, a mulher transgênero deve se adequar ao guia de orientação sexual, mesmo que se trate de um caso de violência por razão de gênero. Apesar da conquista em relação às crianças, há uma enorme perda em relação a esse grupo tão vulnerável.

As Diretrizes de 2002 trazidas pelo ACNUR sobre a Perseguição baseada no Gênero dividemponto a ponto as razões pelas quais o solicitante de refúgio pode justificar ter sofrido um grave temor de perseguição: raça, religião, nacionalidade, grupo social específico e opinião política. Elas reconhecem que as mulheres possuem experiências diferentes das vivenciadas pelos homens e admitem a ineficácia protetiva de direitos humanos da Convenção de 1951, entretanto, ao mesmo tempo, insistem em deixar a violência sofrida pela mulher em segundo plano, sendo apenas uma interpretação extensiva daquilo que já existe e não coloca a problemática feminina em primeiro plano. Da mesma forma que as Diretrizes fazem, farei essa divisão pontual assinalando as problemáticas da interpretação extensiva por se tratar de uma visão androcêntrica.

\section{Raça}

As Diretrizes do ACNUR afirmam que a raça a qual é referida é aquela do senso comum, incluindo os grupos étnicos que são definidos por raça. Com essa afirmação, o guia prossegue abrangendo a questão feminina como uma razão persecutória caso a elas seja dado

\footnotetext{
${ }^{13}$ Conceito que abrange as pessoas que se identificam com o gênero que lhes foi atribuído desde o nascimento (De Jesus, 2012).

${ }^{14}$ Grupo diversificado de pessoas que não se identificam com o gênero, em graus distintos pelos papeis sociais e expectativas relacionadas ao gênero que lhe atribuíram no momento do nascimento (Ibidem)
} 
um tratamento específico distinto ao dos homens e, por isso, especialmente perseguidas através da violência sexual ou do controle reprodutivo.

A extensão interpretativa em relação ao gênero nesse item traz uma preocupação à proteção a mulher em relação à perseguição por violência principalmente no caráter sexual partindo do princípio do controle reprodutivo estar inserido em sua amplitude - ou seja, essas mulheres seriam duplamente perseguidas: tanto em razão de raça e especificamente, humilhadas pela condição de mulher, sofrendo com a violência sexual.

\section{Religião}

No âmbito religioso, o ACNUR em suas diretrizes traz a questão de códigos de conduta e papéis dentro da religião que punam a mulher de maneira diferenciada e dessa forma ela corra riscos específicos. As diretrizes reconhecem que essa seria uma razão para que ela recuse a adoção da religião de sua localidade, consequentemente, por sua recusa, sofra perseguições e precise tornar-se refugiada.

O guia de diretrizes do ACNUR também traz a questão de uma religião oficial ou imposições estatais que perseguem uma mulher. As próprias diretrizes exemplificam o caso da recusa de uma mulher de seguir uma religião oficial por questões que o papel da mulher está guiado por esta. As diretrizes, entretanto, são específicas no que diz respeito a países em que as instituições do Estado, as leis e as doutrinas não possuem separação clara em relação à religião.

Cabe ressaltar que, uma vez que as instituições dos Estados não possuem separação com a religião no escopo de proteção do temor da perseguição de gênero nesse caso, a atitude da mulher em relação a negação desses valores seria uma forma de opinião política. Por estar no tópico de religião e abordá-la como opinião política, pode-se falar, portanto, que esse ponto se torna até mesmo ineficaz por não possuir aplicação prática, apenas uma exemplificação de algo que não caberia a esse item.

\section{Nacionalidade}

Conforme as diretrizes trazidas pelo ACNUR, o conceito de nacionalidade deve trazer mais que a perspectiva cidadã, compreendendo também um grupo étnico e linguístico que pode ser perseguido. Aqui, é assumida uma questão de que a violência pode ser comumente associada a uma violência sexual dirigida contra mulheres e meninas, inserindo as meninas no rol de vítimas de violência por razão de gênero. 
Assim sendo, o temor de perseguição seria relativo a um grupo étnico específico, mencionando a associação dessa perseguição com a violência sexual especialmente destinada a mulheres e meninas.

\title{
Pertencimento a um grupo social específico
}

Esse é o aspecto das diretrizes que mais incluí pontos para sua interpretação extensiva em relação à perseguição por razão de gênero. O próprio primeiro ponto já adianta essa relevância, pois afirma que as solicitações baseadas no gênero são analisadas no parâmetro deste sem negligenciar, ou considerar, supérfluos as outras razões abordadas.

O segundo ponto trazido traz uma citação do Manual do ACNUR sobre as Diretrizes acerca do Pertencimento a um grupo social específico que diz que:

\begin{abstract}
Um grupo social específico é um grupo de pessoas que compartilha uma característica comum, além do fundado temor de perseguição, ou que é percebido como um grupo pela sociedade. A característica será, em geral, algo inato, imutável ou que é fundamental para a identidade, consciência ou exercício dos direitos de um indivíduo. (ACNUR, Diretrizes sobre Proteção Internacional n. 01, Perseguição baseada no Gênero, no contexto do Artigo 1A(2) da Convenção de 1951 e/ou Protocolo de 1967 relativos ao Estatuto dos Refugiados de 2002)
\end{abstract}

Depois disso, esse guia de diretrizes defende que a mulher pertence a um grupo social específico, sendo um exemplo claro por sua característica inata e imutável. As diretrizes do ACNUR, ainda, afastam a possibilidade de uma crítica em relação ao tamanho do grupo ao qual o gênero feminino se inclui dizendo que não há previsão sobre o tamanho, forma de associação ou se o grupo é coeso na Convenção.

O item deixa evidente que essa é a posição assumida pelo órgão em relação a uma solicitante de refúgio que sofre temor de perseguição por sua condição de gênero. Ao se defender quanto à problemática de a mulher não pertencer a um grupo social específico, o próprio órgão assume sua despreocupação com essa demanda. Ora, a mulher, a exemplo do contexto populacional brasileiro, é um grupo inclusive majoritário numericamente, entretanto, assume características extremamente heterogêneas, possuindo demandas diferenciadas e dificilmente em outros cenários seria considerada como um grupo social específico.

A própria palavra "grupo" remete a algo limitado, ainda mais quando inserida ao lado de "específico" - ou seja, um gênero que compreende algo tão numeroso, não pode ser considerado protegido por esse item. A tentativa de estender sua significação para dentro da perseguição de gênero dentro de um guia demonstra que o Estatuto dos Refugiados não tem interesse em adicionar a perseguição baseada na questão de gênero em seu texto. 
M. Foster (2014, pp. 18-19) apresenta cinco razões problemáticas para interpretar a questão de gênero como um membro de um grupo particular específico, observando os casos específicos ao redor do mundo, em que assumir um temor de perseguição por razão de gênero se baseando no "grupo social específico" é controverso.

O primeiro ponto apresentado por M. Foster é que é desnecessário requerer uma associação voluntária para pertencimento à um grupo social específico. Posner $\mathrm{J}$, da Sétima Corte de Apelações dos Estados Unidos, apontou em Sepulveda que a palavra "social" não cria a necessidade do pertencimento a um grupo fechado como um clube para confinar essa categoria $^{15}$. A autora ainda afirma que grupos individualizados por muitas vezes não possuem ligações entre si, como crianças, mulheres, gays, bissexuais, transgêneros, lésbicas ou intersexuais (LGBTI).

Em segundo lugar, não há necessidade do grupo ser homogêneo ou ter uma coesão interna. O próprio Tribunal de Justiça da Alta Corte da Austrália notou isso em sua decisão Minister for Immigrationand Multicultural Affairs vs. Khawar ('Khawar') em 2002.

O terceiro apontamento feito por M. Foster é em relação ao tamanho do grupo - que pode ser uma família ou um enorme - as mulheres. A proposta de adotar a perseguição de um grupo particular específico implica em dificultar a demanda de seus grupos.

O quarto ponto é que um grupo social não pode ser definido pelo temor de perseguição, por muitas vezes ele não ser compartilhado. Há, também, uma decisão da Alta Corte da Austrália de Dawson J. explicou em seu Applicant $A^{16}$ que há uma questão de maior união entre um grupo que teme pela perseguição ao pertencimento ao grupo, do que um grupo social particular que tem um medo comum de perseguição.

Por último, não é necessário que todos os membros pertencentes ao grupo social específico precisem sofrer com o risco de perseguição por sua existência, assim como na questão de raça e religião. Alguns podem individualmente sofrer com essa perseguição, mas não necessariamente fazer parte do grupo é um risco. No caso da perseguição em relação ao gênero isso dependerá, inclusive, da localidade em que esse grupo se encontra e de como a estrutura patriarcal está impetrada na sociedade.

Como um ganho positivo, em algumas jurisdições ao redor do mundo, o "grupo particular específico" tem possuído leitura extensiva inserindo grupos como vítimas do tráfico humano, grupo com orientação sexual específica. Alguns países da América Latina como

\footnotetext{
${ }^{15}$ Baseado no caso da Sétima Corte de Apelações dos Estados Unidos, SepulvedavsGonzales ('Sepulveda’) de 2 de outubro de 2006.

${ }^{16}$ Applicant A de 1997 da Alta Corte australiana que definiu a questão de refugiados em seu texto.
} 
Paraguai, México, Guatemala, Uruguai, El Salvador, Costa Rica e Venezuela, por exemplo, já reconhecem gênero ou sexo como um cenário independente para requisito do status de refugiada (FOSTER, 2014, pp. 25-26).

\section{Opinião política}

Há cenários em que a mulher pode ser perseguida em razão de opinião política, por exemplo. Uma decisão da corte da Nova Zelândia entendeu que essa perseguição por opinião política deve ser orientada a refletir a diferença das experiências femininas construídas no contexto específico geográfico, histórico, político e sócio cultural do país de origem (Ibidem) 17 .

Sob a égide da opinião política, conforme o guia do ACNUR, seria expor uma opinião crítica em relação aos papéis de gêneros, um inconformismo em relação a tradições, políticas ou métodos e essa opinião trazer como consequência um fundado temor de perseguição.

As diretrizes do ACNUR prosseguem e afirmam que:

\footnotetext{
As mulheres são menos propensas do que os homens a se engajar em atividades políticas de alto perfil e, em geral, se envolvem em atividades políticas em níveis mais baixos, que refletem os papéis de gênero dominantes. (ACNUR, 2002)
}

Nesse sentido, é citado, por exemplo, o papel da mulher trabalhando como enfermeira de soldados rebeldes enfermos e que à elas são atribuídas a opinião política dos parentes homens, estendendo a elas uma possível perseguição em relação ao pertencimento a essa opinião política. Esse ponto termina reconhecendo que as mulheres podem se negar a participar de tais atividades e por isso podem ser perseguidas em razão disso.

Considero que afirmar que mulheres são menos propensas do que os homens a se engajar em atividades políticas de alto perfil é problemático. Buscar protegê-la é também reconhecer seu papel com relação de igualdade em relação ao gênero masculino. Por mais que seja algo comumente percebido, a mulher muitas vezes também possui opiniões políticas independentes de homens que pertencem às suas famílias e, em razão disso, sofrem temor de perseguições até mesmo no âmbito doméstico com violência, por exemplo.

Cabe mencionar, a título de ilustração, o caso da Ditadura Civil Militar Brasileira. As mulheres que possuíam opiniões políticas distintas da predominante, orquestrada pelo governo vigente, sofriam perseguições específicas a sua condição de mulher - eram torturadas e estupradas por parte do aparelho estatal não só para a obtenção de uma informação ou na busca de prazer sexual por parte do homem, mas eram subjugadas por sua condição de

\footnotetext{
${ }^{17}$ Decisão da Corte da Nova Zelândia, Refugee Status Appeal Authoriry ('RSAA'), decisão no 76044 de 2008.
} 
mulher, com o objetivo de fragilizar e humilhar mulheres tidas como opositoras ao regime (SABADELL, 2011).

Estendendo a experiência brasileira para outros regimes autoritários vivenciados por algumas mulheres em seus países, cabe reiterar que essas mulheres sofrem perseguição não por serem opositoras aos regimes vigentes apenas: mas por serem mulheres. De acordo com as diretrizes do ACNUR, as mulheres são menos propensas do que homens a se engajar em atividades políticas, entretanto, ao serem perseguidas por um regime persecutório enfrentam uma tortura diferenciada. A necessidade de afirmar que mulheres são uma minoria numérica na participação política de alto perfil nesse ponto desvaloriza sua luta, além de minimizar seu sofrimento duplo quando perseguida.

As diretrizes do ACNUR de 2002 representam o que é chamado, pela doutrina do Direito Internacional de soft law, o direito que é maleável e não obrigatório. É um direito alternativo, com normas relativizadas. (Oliveira e Bertoldi, 2010) A partir da exposição de item a item, pode-se dizer, portanto, que essas Diretrizes do ACNUR incluem a condição da perseguição de gênero de forma bastante questionável. Além disso,Laliberté-Beringar(2002) afirma que o fato Estatuto dos Refugiados não incluira perseguição em relação à violência de gênero mostra uma lacuna jurídica estabelecida pelo ACNUR ao não explicitar, apesar de considerar uma questão forte o suficiente para a criação de diretrizes.A não inserção da mulher no Estatuto dos Refugiados do ACNUR é admitir que as normas referentes à mulher são maleáveis e relativizadas.

\section{Violência de gênero e a dicotomia público/privado}

O feminismo interseccional surge com a demanda das mulheres negras que criticaram a construção da mulher a partir de uma experiência universalista. (NAPLES, 2008). Ele é uma análise detalhada de recortes necessários para o estudo feminista, a partir de dimensões de raça, classe, opção sexual e realizar, a partir dessas diferenças, uma construção de um estudo aprofundado da experiência feminina.

Sob uma perspectiva do feminismo interseccional e das ondas feministas, o feminismo surgiu como forma de luta das mulheres contra a hierarquia de gêneros. Traçando um paralelo com a realidade brasileira, a primeira onda feminista foi no século XIX, no qual as mulheres começaram a assumir uma postura que incomodasse não somente os homens, mas também a sociedade em que elas viviam. Já a segunda onda iniciou-se em um momento de crise democrática e, por isso, as mulheres ajudaram na luta contra a ditadura militar e, então se 
formou o Movimento Feminista pela Anistia. Por último, na década de 90, a terceira onda ascendeu para discutir todas as teorias e todos os paradigmas estabelecidos nas ondas anteriores (RIBEIRO, 2013).

Uma das mais fortes críticas feitas a uma abordagem inclusiva de gênero é a questão público-privada. A violência que afeta a mulher por razões de gênero é enxergada sob a proteção social e jurídica do âmbito privado. Enquanto isso, a violência pública é relacionada à experiência masculina. Seguindo esse pensamento, o próprio Direito dos Refugiados possui um foco na experiência de perseguição masculina se tornando a norma (FOOTE, 1994).

Na Convenção de 1951, é utilizado exclusivamente pronomes masculinos. A política de nomeação afeta, primeiramente, a questão da dicotomia artificialmente criada do refugiado político em relação ao econômico (HAJDUKOWSKI-AHMED apud GILES, 1996, p. 29), conferindo maior legitimidade ao econômico enquanto a mulher é exposta à violência em ambos os casos de maneira específica. Em segundo lugar, a própria Convenção separa a esfera pública da privada, valorando a questão política para o reconhecimento do refugiado. Por fim, pode-se citar que as políticas governamentais aplicadas, as pesquisas e agências internacionais utilizam uma perspectiva do Norte $^{18}$ em detrimento do Sul, não levando em conta a experiência do Sul, nem a experiência da mulher. (HAJDUKOWSKI-AHMED, 2009, p. 34).

Tanto o Estatuto do Refugiado quanto o Direito Internacional dos Direitos Humanos, as experiências femininas são subsumidas em relação à estrutura de direitos dos homens (OKEN apud OXFORD, 2014). Assim como colocado por Boyd (OXFORD apud BOYD, 2014, p. 160), a definição de refugiado colocada pelos documentos do ACNUR é insensível à questão de gênero, além de cega, baseadas no protótipo masculino em seu pior.

Na crítica à perspectiva liberal adotada pelo Estatuto do Refugiado, há a visão de que o liberalismo promove uma forte dicotomia entre o público e o privado, que é vista fortemente nas questões de gênero (PATEMAN apud OXFORD, 2014, p. 160-161). O homem é enxergado como capaz de realizar as atividades da esfera pública como o poder da vida pública - aquele que controla as atividades perante o Estado - enquanto à mulher é destinada a doméstica. Isso implica em uma estrutura de leis patriarcal vista sob uma perspectiva liberal que fortalece essa dicotomia. Por outro lado, a ligação entre o público e privado é fortalecida no que diz respeito aos tipos de perseguição sofridos pela mulher, como por exemplo, o

\footnotetext{
${ }^{18}$ O Norte e o Sul são utilizados de maneira metafórica, utilizando assim a conotação socioeconômica em detrimento da questão geográfica. (Hajdukowski-Ahmed, 2009)
} 
casamento forçado, a violência doméstica ou a circuncisão feminina (OXFORD, 2014, p. 160161).

O caso citado por Oxford (2014, p. 164-165) em seu artigo é o de Zeinab, uma mulher da Somália que conseguiu refúgio nos Estados Unidos porque ela foi estuprada durante a Guerra Civil de seu país. Contudo, a motivação para tal pedido não foi o abuso e sim a violência doméstica que ela estava sofrendo em seu casamento arranjado. Zeinab conta que a violência teve início após o nascimento do seu primeiro filho, quando seu marido começou a violentá-la na frente de sua mãe e irmãs, mas elas nada podiam fazer pois não possuíam artifícios para auxiliar Zeinab. Contudo, ele começou a utilizar armas para agredi-la, até que chegou ao ponto de cortá-la com uma faca. A partir de então, ela percebeu que a situação poderia piorar, passou a sentir-se ameaçada e perseguida, não podendo permanecer mais em seu local de origem para a proteção de sua vida.

Com a ajuda da sua família, então, Zeinab foge para os Estados Unidos, ainda com medo de que seu marido fosse atrás dela. Isso demonstra que a perseguição não cessa para o refugiado, mesmo que ele já se encontre em outro país. Apesar do gravíssimo temor de perseguição em razão de seu gênero, ela mentiu em sua entrevista dizendo que foi estuprada durante a Guerra Civil da Somália e que nesse processo foi afastada de seu marido.

A história contada por ela não foi apenas para conseguir sair do seu país, mas também para fugir de um relacionamento abusivo, pois se ela contasse sobre seu marido, não conseguiria o refúgio e, talvez, após sua entrevista seu marido seria avisado do seu paradeiro e iria atrás dela e, se caso ela fosse deportada, sofria grave temor de ser morta por ele.

Ao longo de seu texto, Oxford cita não apenas o caso de Zeinab, mas de outras mulheres. Ao citar outros exemplos, percebemos que as mulheres estão constantemente inseridas em um contexto de uma sociedade patriarcal, um exemplo são as entrevistas de elegibilidade nas quais elas não são ouvidas - o marido fala por toda a família. Esse tipo de prática impede a saída dessas mulheres de relacionamentos possivelmente abusivos e, principalmente, não permite um estudo exato e pesquisas específicos acerca dessas mulheres e seus filhos. Outras, assim como Zeinab, precisam deixar suas crianças e por isso, são silenciadas durante suas entrevistas e até mesmo chegam ao ponto de inventar histórias para conseguirem obter o status de refugiada. Isso ocorrepois a mulher está inserida em um silêncio social constante, agravado pela vulnerabilidade da condição de refugiada.

Pode-se concluir, a partir do exposto, que a proteção à violência de gênero sofrida pela mulher é tratada como uma zona de penumbra para a conquista de direitos uma vez que é 
considerada uma violência privada e, por isso, o Estado tem dificuldade em regular o assunto. Isso se reflete na elaboração das normas que norteiam a refugiada, pois o Direito Internacional busca regulamentar aquilo que é público - ou seja, a experiência masculina quanto à perseguição que caracteriza sua fuga forçada e consequentemente, sua solicitação de refúgio. Ao estabelecer critérios como raça, opinião política, religião, nacionalidade e pertencimento a um grupo social específico, o Estatuto evidencia sua preocupação com questões políticas e públicas, deixando de lado a experiência feminina de perseguição por questões de gênero, aprofundando uma dicotomia entre o público e o privado.

\section{Considerações Finais}

O ACNUR reconhece que há a necessidade de proteger as mulheres que saem de seu lugar para outro por um grave temor de perseguição em razão de seu gênero. Pode-se falar que as constantes lutas das mulheres ao longo do século XX surtiram efeito dentro de uma Organização eurocêntrica e de estrutura patriarcal. Apesar do ganho, não se pode negar que é o início de um longo caminho para uma igualdade plena de gêneros que não parece próxima de ser conquistada. Ao elaborar apenas diretrizes, não é admitida a necessidade de preencher a lacuna jurídica que há ao fornecer apenas cinco razões pelas quais alguém pode solicitar o reconhecimento como refugiada. Raça, nacionalidade, religião, opinião política e pertencimento a um grupo social específico não abarcam as pessoas que fogem por perseguição de seus locais de origem. Fugir é uma condição de vulnerabilidade, sendo mulher, essa é uma tarefa que a expõe ainda mais à vulnerabilidade. Enxergar a razão de gênero como justificativa para se valer do status de refugiada em um estatuto é proteger a chegada da mulher refugiada em um local completamente desconhecido e saber que ela está salvaguardada por uma legislação aplicável e eficaz.

As diretrizes que reconhecem que há uma perseguição por razões de violência de gênero e ela gera a fuga de mulheres de seu local de origem. Do ponto de vista jurídico, entretanto, essas diretrizes não possuem a mesma eficácia que as normas e definições contidas no Estatuto. Isso se reflete nas decisões jurisprudenciais ao redor do mundo, que não consideram a motivação patriarcal para a solicitação do refúgio. A consequência disso é que as refugiadas temem admitir a real razão de seu refúgio durante a entrevista de admissão. Dessa forma, elas preferem justificar sua fuga de forma que se encaixe nas determinações do Estatuto de 1951, escondendo as marcas de uma sociedade que as oprimiu de maneira 
silenciosa. Calar essas mulheres diante dessa solicitação é mais uma forma de violentar refugiadas - que já estão em um alto nível de vulnerabilidade.

É inegável que a estrutura na sociedade a qual vivemos é, em geral, assentada com base no patriarcalismo - a autoridade dos homens em relação às mulheres, de forma institucionalizada. O reflexo disso é a legislação e a jurisprudência existente em relação às refugiadas, que permanecem em segundo plano, sem perspectiva de ajustes. Considerando que o Estatuto e as próprias diretrizes são baseados sob uma perspectiva eurocêntrica, não é de interesse desses países regulamentar os direitos de refugiados com fluxos tão intensos quanto os atuais, com mais de 51 milhões de pessoas que saem de suas casas para arriscar um futuro incerto. Reconhecer que a fuga por razão de perseguição em razão de gênero é justificativa para a entrada de uma refugiada em seu país, é permitir que mais uma categoria perpetrasse nesses países, o que não é interessante.

Os tempos mudam, os fluxos se intensificam, a sociedade não é a mesma. O conceito de refugiada é fluido e dinâmico, entretanto, baseia-se em um Estatuto estático. Anos depois da elaboração do estatuto, não há alteração em seu texto, mas há uma desconstrução social constante - as mulheres conquistam cada vez mais espaço e emancipação dentro da sociedade, hoje, são chefes de família, muitas vezes fogem sozinhas, porém, não adquirem direitos, mas encontram barreiras aos quais devem se esquivar ao chegar ao seu destino.

Isso leva a dicotomia do androcentrismo - que posiciona os homens e o que diz respeito a eles na esfera pública, dando maior poder a eles, enquanto o que diz respeito a mulheres é da esfera privada, doméstica. Por isso, então, há uma limitação clara da proteção jurisdicional internacional. As mulheres permanecem, ainda, constantemente submetidas às desvantagens de seu gênero em detrimento dos homens. Não são levados em consideração casos de clara perseguição de gênero - como quando estão tentando fugir de casamentos forçados por suas famílias, violência doméstica dos seus maridos, mutilação genital.

Apesar da visão crítica, não podemos negar uma evolução nas leis e políticas de refúgio quando se trata da questão de gênero. As diretrizes, nesse sentido, são uma evolução jurídica e social e um reconhecimento de um problema estrutural. Reconhecer isso é importante e as diretrizes são parte desse processo que se inicia. É inegável, porém, que esse crescimento é lento e não se mostra eficaz por não ser aplicável na realidade prática. Portanto, constata-se que essa é uma pauta necessária ao feminismo, que deve proteger essa mulher que está em uma situação tão vulnerável. O medo de não ser reconhecida como refugiada e conquistar esse direito humano a silencia diante de sua condição e o temor do retorno ao seu 
local de origem - e aos problemas do local de origem - permanecem. Reconhecê-la como contemplada pelo Estatuto do Refugiado de fato é, acima de tudo, romper uma dentre tantas barreiras que essa mulher enfrenta ao chegar ao lugar final de destino.

Valores e comportamentos sociais são impostos a mulheres a todo tempo, em razão do que somos, não apenas pela forma como a qual nascemos. $\mathrm{O}$ corte realizado nesse trabalho reflete essa estrutura já vivenciada pela condição de mulher, agravada por um temor de perseguição e de uma violência específica de gênero que força a sair de seu lugar.

A mulher que sai de seu lugar original para a localidade a qual se destina, quer ser protegida para a tentativa de reescrever sua história em outro local, esse que pode ser, em muitos casos, completamente desconhecido. Ao chegar a seu destino haverá barreiras culturais, linguísticas, econômicas. Construir mais uma barreira é ampliar a marginalização em relação às mulheres. Poder admitir a razão pela qual foi obrigada a sair de suas raízes é protegê-la de fato dessa perseguição; é permitir que ela seja livre para possuir um direito humano e não ter que mentir - e, consequentemente, conviver com o medo de que a verdade seja revelada. É permitir que a violência tanto física quanto mental vivenciada anteriormente não se repita e não se permita dentro do lugar de destino.

A criação e conservação de leis e políticas que protejam as mulheres é fundamental, uma vez que elas permanecem vítimas da violência em razão de seu gênero. No contexto de fronteiras que se fecham, é emergencial um auxílio a refugiadas mulheres, que precisam de ajuda emergencial. Por isso, ao estabelecer apenas diretrizes, o ACNUR em seu estatuto não lhes dá a proteção adequada e delimita em apenas cinco razões para o temor de perseguição tratando a questão de gênero como secundária e, consequentemente, menos importante. $\mathrm{O}$ Estatuto dos Refugiados foi criado para proteger as refugiadas, mas não abrange sua totalidade. Isso traz inegavelmente uma lacuna jurídica, que em sua aplicabilidade prática traz consequências gravosas a sociedade torna-se questionável e permanente desde sua criação, que continua silenciando diversas outras razões pelas quais alguém pode sofrer um grave temor de perseguição, não admitindo outras razões senão as cinco do Estatuto dos Refugiados de 1951.

\section{Referências}

ACNUR - Convenção Relativa ao Estatuto dos Refugiados de 1951. Disponível em: $<\mathrm{http}$ ///www.acnur.org/t3/fileadmin/Documentos/portugues/BDL/Convencao_relativa_ao_Est atuto_dos_Refugiados.pdf>. Acesso em 29 de junho de 2017. 
ACNUR - Diretrizes sobre Proteção Internacional n. 01, Perseguição baseada no Gênero, no contexto do Artigo 1A(2) da Convenção de 1951 e/ou Protocolo de 1967 relativos ao Estatuto dos Refugiados. Disponível em: $<$ http://www.acnur.org/t3/fileadmin/Documentos/portugues/Publicacoes/2013/Manual_de_pr ocedimentos_e_criterios_para_a_determinacao_da_condicao_de_refugiado.pdf $>$. Acesso em 28 de junho de 2017.

BAUMAN, Zygmunt. Medo Líquido. 1 ed., São Paulo: Zahar, 2008. 240 p.

CARVALHO, M. E. P.; ANDRADE F. C. B.; JUNQUEIRA, R. D. Equidade de Gênero e Diversidade Sexual na Escola: por uma prática pedagógica inclusiva. João Pessoa: Editora Universitária - UFPB, 2009.

DE JESUS, Jacqueline Gomes. Orientações Sobre Identidade de Gênero: Conceitos e Termos. Brasília, 2012. Disponível em: <http://pt.scribd.com/doc/87846526/Orientacoessobre-Identidade-de-Genero-Conceitos-e-Termos> Acesso em 3 de agosto de 2017.

DE PAULA e PRONER. Convergência e Complementariedade Entre as Vertentes de Proteção Internacional de Direitos Humanos.Revista da Faculdade de Direito - UFPR, Curitiba, n.48, p.219-241, 2008.

ELSHTAIN, Jean B. Public Man, Private Woman.Princeton University Press, 1981. 408p.

FOSTER, Michelle. Gender In Refugee Law; "Why we are not there yet". 1 ed. New York: Routledge, 2014. 296p.

HADDAD, Emma. The Refugee in International Society Between Sovereigns. Cambridge Studies in International Relations, 2008. 254p.

HAJDUKOWSKI-AHMED, KHANLOU e MOUSSA. Not Born a Refugee Woman, $1^{\text {a }}$ ed., Berghahn Books, 2009. 336p.

FOOTE, Victoria. Refugee Woman as a Particular Social Group: A Reconsideration. York, $1994 . \quad$ Disponível em <https://refuge.journals.yorku.ca/index.php/refuge/article/viewFile/21842/20511>Acesso em 9 de novembro de 2017.

FREEDMAN, Jane.Gendering the International Asylum and Refugee Debate. PalgraveMacmillan, 2015. 246p.

JUBILUT, Liliana Lyra. O Direito Internacional dos Refugiados. 1. ed. São Paulo: Método, 2007.

LALIBERTÉ-BERINGAR, Danièle. Problématique du genre dans les situations de détresse : les cas de réfugiés en Afrique. Refuge. Volume 20. Montréal, 2002.

NAPLES, Nancy A. Crossing Borders: Feminism, Intersectionality and Globalisation. Magrill, $2008 . \quad$ Disponível em <"http://w3.unisa.edu.au/hawkeinstitute/publications/downloads/wp36.pdf">Acesso em 9 de novembro de 2017. 
OLIVEIRA, Liziane Paixão Silva; BERTOLDI, Márcia Rodrigues. A Importância do Soft Law na Evolução do Direito Internacional. Disponível em: < http://cidp.pt/publicacoes/revistas/ridb/2012/10/2012_10_6265_6289.pdf >. Acesso em15 de novembro de 2017.

OLSEN, Frances. El Sexo del Derecho. Identidad Femenina y Discurso Jurídico. Editorial Biblos, Colección Identidad, Mujer y Derecho. Buenos Aires, 2000.

OXFORD, Connie. Gender In Refugee Law; “Where Are The Women?" 1ed. New York: Routledge, 2014. 296p.

RIBEIRO, Djamila. As Diversas Ondas do Feminismo Acadêmico. Carta Capital. Disponível em: <https://www.cartacapital.com.br/blogs/escritorio-feminista/feminismoacademico-9622.html>. Acesso em 28 de junho de 2017.

SABADELL, Ana Lúcia.Anistia: A política além da justiça e da verdade. Disponível em: $<$ http://revista.arquivonacional.gov.br/index.php/revistaacervo/article/view/371/371>Acesso em 29 de junho de 2017.

WALDELY, Aryadne B. Direito Internacional dos Refugiados: Uma Análise HistóricoPolítica. Direito Internacional e Direitos Humanos III. 23ª ed. Florianópolis, 2014. 